\title{
Design como recurso facilitador do processo de inclusão de crianças com autismo
}

Design as a facilitator resource of the process of inclusion of children with autism

\author{
Maria Lúcia Espanhol \& Renata Vilanova Lima
}

design em parceria, recurso facilitador, inclusão, autismo

\begin{abstract}
Este artigo apresenta o desenvolvimento de um projeto de Design que resultou em um recurso facilitador para o processo de inclusão de um menino com autismo na Educação Infantil. A relevância desse tema se dá pela dificuldade de socialização e comunicação da condição do autismo e pelo crescente número de diagnósticos. Foi observado um menino com autismo, não verbal, de cinco anos de idade e com grandes dificuldades de interagir com os colegas na escola, além da constante tendência a se isolar de todos. Pela observação participante e a abordagem metodológica do Design em Parceria foi possível identificar elementos os quais o menino demonstrava interesse. A partir desses elementos aliados com o projeto pedagógico em andamento da turma foi elaborado uma atividade com o objetivo de que todos pudessem participar. A atividade consistia em montar um "minifloresta", visto que as crianças estavam aprendendo sobre a natureza no período em que foi proposto o projeto, o que atraiu a curiosidade de todos para a atividade. A informação transmitida pelo novo recurso, a imagem representativa de uma floresta, propiciou a interação da criança com autismo com seus colegas. O novo recurso de Design atuou como mediador do conhecimento e do processo de inclusão do menino com autismo.
\end{abstract}

partnership design, facilitator resource, inclusion, autism

This article presents the development of a Design project that has resulted in a facilitating resource for the process of inclusion of a boy with autism in Early Childhood Education. The relevance of this theme is due to the difficulty of socialization and communication of the condition of autism and the increasing number of diagnoses. It was observed a boy with autism, nonverbal, of five years of age and with great difficulties of interacting with the colleagues in the school, besides the constant tendency to isolate of all. Through participant observation and the methodological approach of Design in Partnership, it was possible to identify elements that the boy showed interest. From these elements allied with the ongoing pedagogical project of the class, an activity was elaborated so that everyone could participate. The activity consisted of putting together a "minifloresta", since the children were learning about nature in the period in which the project was proposed, which attracted the curiosity of all for the activity. The information transmitted by the new resource, the representative image of a forest, allowed the child to interact with autism with his colleagues. The new Design resource acted as mediator of the knowledge and process of inclusion of the child with autism.

\section{Introdução}

Este artigo tem por objetivo apresentar o caminho percorrido na elaboração de um recurso pedagógico, facilitador no processo de interação/inclusão de uma criança com autismo na Educação Infantil e os frutos desse projeto de Design que proporcionou formas de aprendizado e socialização a um sujeito com autismo utilizando a informação aplicada ao Design.

O projeto de Design que aqui será relatado é um recorte do Trabalho de Conclusão de Curso (TCC), desta autora, na graduação em Desenho Industrial na Universidade Federal Fluminense, (DI-UFF). Esse projeto foi fundamentado no caráter interdisciplinar do Design, buscando caminhos para uma situação (problema) cada vez mais comum nos ambientes de ensino aprendizagem: a inclusão de crianças com autismo no ensino regular.

Anais do 9 $\mathrm{CIDI}$ e 9 CONGIC

Luciane Maria Fadel, Carla Spinillo, Anderson Horta,

Cristina Portugal (orgs.)

Sociedade Brasileira de Design da Informação - SBDI

Belo Horizonte | Brasil | 2019

ISBN $978-85-212-1728-2$
Proceedings of the 9th CIDI and 9th CONGIC

Luciane Maria Fadel, Carla Spinillo, Anderson Horta,

Cristina Portugal (orgs.)

Sociedade Brasileira de Design da Informação - SBDI

Belo Horizonte | Brazil | 2019

ISBN 978-85-212-1728-2 
A inclusão de pessoas com deficiência no ensino regular vem ocorrendo de forma gradual há mais de 20 anos, sustentada por uma série de políticas públicas, incluindo a Constituição Federal de 1988 que ampara no art. 205 a Educação como 'direito de todos e dever do Estado e da família', (Brasil, 1988). No caso de crianças com autismo há uma percepção de que este público tenha aumentado no ambiente escolar, constituindo-se um desafio para todos os integrantes da escola essa inclusão, devido às características específicas da condição do autismo.

De acordo com o Manual Diagnóstico e Estatístico de Transtornos Mentais (DSM-5), são características do Transtorno do Espectro Autista (TEA) prejuízos persistentes na comunicação e na interação social, além de padrões restritos e repetitivos de comportamento, interesses ou atividades. Tais sintomas começam ainda no "início da infância e limitam ou prejudicam o funcionamento diário", podendo até serem observados sintomas antes dos 12 meses de idade, (American Psychiatric Association, 2014).

A relevância deste tema se dá pelo aumento do número de diagnósticos, embora no Brasil não haja estatísticas, nos Estados Unidos os diagnósticos passaram de um caso a cada 166 crianças em 2004 para 1 caso diagnosticado a cada 59 crianças em 2018, (Centers for Disease and Prevention, 2018).

A intenção de projetar para um público tão específico faz com que o designer procure formas de compreender esse sujeito (seja pela observação, interação, percepção, convívio, análise do ambiente) entendendo quais são suas reais necessidades/desejos, e de que modo o Design pode contribuir na proposição de ações/projetos que possam atenuar possíveis dificuldades características da condição do autismo.

A proposição dessas ações/projetos para um grupo de sujeitos, que é considerado minoritário em relação à sociedade como um todo, e que apresentam a condição do autismo exige a efetiva participação do designer junto a esse grupo de pessoas. Esse contexto pode ser considerado como Design Social, onde segundo Couto, 'existe um pressuposto básico que é a preservação do direito do designer de pesquisar no campo e, juntamente com as pessoas e a partir delas, contar com a sua sensibilidade para captar a realidade, por mais complexa e multifacetada que seja', (2017, p. 30).

A diversidade encontrada em sala de aula, ao mesmo tempo, que enriquecedora é também desafiadora. As características comportamentais do sujeito com autismo, muitas vezes exigem a adaptação de recursos pedagógicos. A atitude projetual do designer, de forma conjunta com a escola, pode enriquecer a concepção desses recursos, contribuindo para a edificação de uma escola inclusiva.

A Declaração de Salamanca, foi um significativo marco internacional para a educação inclusiva, e determina uma importante premissa da escola inclusiva:

Princípio fundamental da escola inclusiva é o de que todas as crianças devem aprender juntas, sempre que possível, independentemente de quaisquer dificuldades ou diferenças que elas possam ter. Escolas inclusivas devem reconhecer e responder às necessidades diversas de seus alunos, acomodando ambos à todos através de um currículo apropriado, arranjos organizacionais, estratégias de ensino, uso de recurso e parceria com as comunidades, (UNESCO, 1994, p. 5, grifo nosso).

O Design tem muito a contribuir para a edificação da escola inclusiva, seja na concepção de recursos, tecnologias ou ações que promovam a interação de crianças típicas com aquelas que possuem alguma necessidade diversificada de aprendizagem. Para a realização desses projetos é importante que o designer esteja nesses locais e estabeleça parcerias, coletando informações, observando atitudes e as relações estabelecidas dos usuários com o ambiente. $O$ projeto que aqui será descrito teve a participação do sujeito principal, o menino Bê, que embora não pudesse se expressar por palavras, a todo o tempo indicava quais eram os seus desejos, e a partir deles em consonância com os interesses dos demais alunos é que se desenvolveu 
esse projeto em parceria.

Nesse contexto podemos afirmar que esse projeto é resultante de um Design em Parceria, onde segundo Farbiarz e Ripper a autoria 'é uma conjunção dos sujeitos designer (com suas competências, suas habilidades, e suas escolhas/ações), usuário/público/comunidade/parceiro (também com suas competências, suas habilidades, e suas escolhas/ações) e o meio ambiente (com suas possibilidades)', (2011).

Para o entendimento do processo desse projeto de Design em Parceria este artigo está organiza do em seis partes: 1) Introdução com algumas considerações a respeito do tema deste artigo; 2) Informações sobre o contexto do projeto; 3) Algumas experimentações que contribuíram para a definição do projeto; 4) A descrição do projeto; 5) A proposição, onde foi observado o usuário interagindo com o novo recurso pedagógico projetado; 6)Considerações finais.

\section{Contexto do projeto}

O projeto, desenvolvido em uma escola de Educação Infantil localizada no município de Niterói - RJ, teve como foco a observação de uma criança autista, o qual atribuímos o nome imaginário de Bê. Inicialmente a observação, de forma participativa, objetivava o reconhecimento de como funcionava a dinâmica da escola, o relacionamento de Bê com seus colegas, professores e mediadores. De acordo com Gray 'a observação envolve o olhar sistemático sobre as ações das pessoas e o registro, análise e interpretação de seu comportamento', (Gray, 2012, p. 321).

O sistema analisado foi a inclusão de crianças com autismo na Educação Infantil, que tem por meta o desenvolvimento integral da criança nos aspectos físico, psicológico, intelectual e social. Para ocorrer esse desenvolvimento há a premissa de professores capacitados, mediadores de acordo com a necessidade, materiais didáticos adaptados, brinquedos e demais recursos de acordo com a necessidades da escola.

A escola adota a abordagem da pedagogia de projetos, onde as atividades partem do interesse das crianças, sejam curiosidades ou brincadeiras e, a partir desse interesse são elaboradas e orientadas. As crianças são incentivadas a colaborarem umas com as outras para que consigam compreender e resolver os diversos problemas que as cercam. Nessa perspectiva, segundo Ribeiro e Oliveira o papel do professor é 'instigar as crianças a se tornarem cada vez mais ávidas por tocar, experimentar, sentir, fazer, conhecer, vivenciar, tornando-se corresponsáveis por suas conquistas nos campos do conhecimento, da cultura, das sensações, das emoções...', (Ribeiro \& Oliveira, 2017, p. 14).

As observações foram feitas duas vezes na semana, em dias alternados, durante dois períodos letivos. No primeiro dia foi possível ter uma dimensão de como o caminho da inclusão depende muito das pessoas que estão a volta do sujeito com autismo. O menino Bê, cujo diagnóstico de autismo iniciou-se após seu ingresso na escola, não verbal, passava grande parte do tempo 'pedindo' para ir pra casa. A forma de pedir era: correr até a porta e tentar sair ou pegar sua mochila e puxar pela mão alguém que conhecesse, ou a mediadora ou a professora, para ir até à porta. Em outros momentos fazia algumas atividades auxiliado pela sua mediadora e longe da turma. Sua presença no parque era frequente, em especial no balanço, entretanto, eram raros os momentos em que interagia com seus colegas.

Na segunda semana houve uma mudança na rotina para o menino Bê, sua mediadora, com quem ele passava a maior parte do tempo, precisou ausentar-se definitivamente. Embora sempre houvesse alguém o acompanhando, quase sempre uma estagiária, seu comportamento mudou, passou um período tentando 'fugir' de todos a sua volta, como se não ter sempre a mesma pessoa ao seu lado implicasse em não querer ter ninguém. De acordo 
com o DSM-5 uma das características de padrões de comportamento restritos e repetitivos é a adesão inflexível a rotina, que pode resultar em 'sofrimento extremo em relação a pequenas mudanças', (American Psychiatric Association, 2014, p. 94).

Após um período de aproximadamente um mês o menino Bê aparentemente estava mais acostumado com sua rotina de não ter sempre a mesma pessoa ao seu lado. Era acompanhado pela estagiária do horário, em geral, a mesma pessoa duas vezes na semana. A partir de então foi possível mensurar características de seu comportamento junto a escola e a todos a ela pertencentes.

O parque era certamente o local de preferência do menino Bê, ficava o máximo de tempo que conseguisse no balanço, mas também cedia lugar para outros colegas quando havia mais crianças no local. Também ficava tranquilo na casinha, típica de parque, que dava acesso ao escorrega, do alto costumava ficar observando a paisagem, repleta de árvores. Quanto às atividades em sala e as aulas com outros profissionais (capoeira, teatro, artes, educação física, biblioteca) sua participação era mínima.

Dentre as situações que poderiam se configurar em problemas para seu desenvolvimento e aprendizagem junto aos colegas, os mais relevantes foram:

- Não haviam materiais pedagógicos adaptados projetados para suas necessidades. A escola continha grande variedade de materiais que eram utilizados por todas as crianças, porém, eram poucos os recursos os quais o menino Bê demonstrava interesse, sua fixação era por colocar o alfabeto e numerais em sequência, sendo esses os materiais que mais brincava. Quando incentivado a desenhar, seja com lápis de cor ou canetinhas mostrava dificuldade em segurar e manipular esses materiais;

- Na maior parte do tempo Bê ficava com a estagiária, que também era responsável em propor atividades. Em aulas como artes e educação física raramente ele participava, já na biblioteca ele permanecia um tempo maior;

- A interação certamente era o maior obstáculo, eram poucos os momentos em que algum coleguinha procurava compartilhar algo com Bê. Também não conseguia ficar na sala de aula por mais de cinco minutos, logo corria para o parque, o balanço e a casinha eram seu refúgio. Quando estava em sala de aula deitava-se no chão sobre um tapete feito de feltro e ficava tateando o tecido, demonstrando interesse. Passava significativa parte do tempo isolado de sua turma, somente na companhia de uma estagiária.

\section{Experimentações}

Para propor algo que provocasse o menino Bê para uma maior participação das atividades em sala de aula e consequente interação com seus colegas, era necessário entender mais suas preferências, além das já observadas que eram o parque, o balanço, a sequência numérica e o alfabeto. Para esses últimos não importava de qual material era feito, brincava com alfabeto de madeira, madeira envernizada ou Etil Vinil Acetato (E.V.A.).

$\mathrm{Na}$ tentativa de obter mais informações para um projeto que o instigasse a interagir, foram elaborados alguns experimentos com materiais novos e já conhecidos por Bê. Na primeira tentativa foi produzida uma caixa encoberta com E.V.A. e dentro dela arroz colorido de azul, mergulhados no arroz figuras de animais marinhos compostas do mesmo material da caixa, os quais ele deveria descobrir tateando no arroz. Brincou menos de cinco minutos e não quis mais saber da novidade, o que nos leva a entender que mesmo demostrando interesse por um alfabeto em E.V.A., esse interesse era somente pela sequência alfabética e não pelo material. Essa tentativa deu-se principalmente por esse material ser farto na escola, possibilitando serem executadas outras atividades posteriormente. 
Outra tentativa foi com papel cartolina colorido, material que também estava disponível na escola. Em uma das observações uma estagiária me informou que ele gostava de cores fortes porque brincava com um cubo vermelho e azul que sua mãe criara. Elaborei pássaros de origami coloridos e seu interesse também não durou mais de cinco minutos. É possível que seu interesse pelo cubo fosse pelo significado, sua mãe que fez, e não pelos papéis coloridos. Outro experimento foi elaborado pela professora da turma, um boneco todo de feltro o qual Bê demonstrou grande interesse em mais de uma situação, sendo esse o material do tapete que costumava deitar e tatear.

Essas experimentações são de significativa relevância quando o principal usuário de um projeto não consegue expressar por palavras quais seus interesses, desejos e necessidades. É uma maneira de definir as características para que o recurso a ser projetado cumpra com o seu propósito de oportunizar a interação de um menino com autismo e seus colegas. Esses ensaios, as opiniões de professores e mediadores, configuram uma participação dos interessados junto ao designer nesse projeto de Design. De acordo com Farbiarz e Ripper, a atitude projetual do Design em Parceria consiste em dedicar tempo a observação das ações cotidianas do usuário em seu ambiente, ouvindo, interagindo, desenvolvendo alternativas, compartilhando soluções e experimentando, (Farbiarz e Ripper, 2011).

\section{0 projeto}

Em síntese das observações e experimentações é possível apontar características que seriam bem aceitas pelo menino Bê para um projeto de recurso pedagógico, como elementos da natureza presente no parque, feltro e cores neutras. O projeto, em uma proposta de inclusão, foi elaborado a partir desses apontamentos e também baseado nas atividades que estavam sendo realizadas com a turma, com o tema "natureza".

O recurso pedagógico foi projetado a partir de um elemento já presente no ambiente, também elaborado por esta autora para o menino Bê, uma estrutura em madeira que para formar um abrigo usa uma tenda em tecido de algodão puro, natural de cor bege. A partir desse elemento, a tenda, é que foi elaborada a atividade pedagógica.

Havia uma incerteza ainda sobre as cores a serem utilizadas no projeto. Na experimentação o menino Bê rejeitou origamis com papéis muito coloridos. Utilizamos o estudo sobre psicologia das cores de Heller, para a definição da paleta de cores, sendo esse elemento importante para tornar o produto visualmente agradável, sem excesso de estímulos que poderiam provocar hiper-reatividades. As cores são percebidas de acordo com a vivência de cada indivíduo, uma cor que é agradável para um pode ser desagradável para outro. Heller definiu como aconchegante a combinação de cores de marrom, verde, amarelo, azul e laranja, (2013).

Partindo do interesse do menino Bê em ficar no parque repleto de elementos da natureza, e da combinação de cores indicativas de aconchego, optou-se por utilizar cores frias e da natureza para compor o recurso, a figura 1 mostra as cores definidas para a atividade. A opção escolhida para compor o recurso pedagógico na tenda consiste em montar uma 'minifloresta', onde foi elaborado um desenho representativo de uma floresta, com árvores e pássaros.

Figura 1: Paleta de cores definida para a atividade

\begin{tabular}{|c|c|c|c|c|c|}
\hline $\begin{array}{ll}\text { C } & 087 \\
\text { M } & 080 \\
\text { Y } & 041 \\
\text { K } & 056\end{array}$ & $\begin{array}{l}\text { C } 000 \\
\text { M } 000 \\
\text { Y } 000 \\
\text { K } 100\end{array}$ & $\begin{array}{ll}\text { C } & 050 \\
\text { M } & 070 \\
\text { Y } & 080 \\
\text { K } & 070\end{array}$ & $\begin{array}{ll}\text { C } & 033 \\
\text { M } & 069 \\
\text { Y } & 100 \\
\text { K } & 030\end{array}$ & $\begin{array}{ll}\text { C } & 056 \\
\text { M } & 045 \\
\text { Y } & 100 \\
\text { K } & 050\end{array}$ & $\begin{array}{ll}\text { C } & 087 \\
\text { M } & 050 \\
\text { Y } & 087 \\
\text { K } & 068\end{array}$ \\
\hline $\begin{array}{ll}\text { C } & 076 \\
\text { M } & 042 \\
\text { Y } & 100 \\
\text { K } & 039\end{array}$ & $\begin{array}{l}\text { C } 079 \\
\text { M } 011 \\
\text { Y } 100 \\
\text { K } 001\end{array}$ & $\begin{array}{ll}\text { C } & 049 \\
\text { M } 049 \\
\text { Y } 062 \\
\text { K } 019\end{array}$ & $\begin{array}{ll}\text { C } & 020 \\
\text { M } & 024 \\
\text { Y } & 100 \\
\text { K } & 000\end{array}$ & $\begin{array}{ll}C & 000 \\
M & 000 \\
Y & 100 \\
\text { K } & 000\end{array}$ & $\begin{array}{l}\text { C } 000 \\
\text { M } 000 \\
\text { Y } 073 \\
\text { K } 000\end{array}$ \\
\hline
\end{tabular}


Além da imagem representativa de uma minifloresta a atividade objetiva também: 1) desenvolver a coordenação motora fina, devido à dificuldade do menino Bê em manipular lápis e canetas; 2) estimular sensações táteis e visuais com diferentes texturas e cores; 3 ) estimular o lúdico com a possibilidade de contar histórias a partir da imagem; 4) estimular sensações olfativas com o uso de essências que remetem aos aromas encontrados na natureza; 5) estimular a cooperação e interação para a montagem da minifloresta; 6 ) estimular a coordenação viso motora, na identificação e ato de montar os elementos; 7) estimular a capacidade de planejar uma tarefa, saber onde cada folha ou pássaro pode ser colocado.

As referências para concepção da minifloresta foram árvores características da região, como a amendoeira e pássaros como tucano, bem-te-vi e canário. A composição da imagem da floresta na tenda foi elaborada da seguinte forma: fixadas permanentemente na tenda estavam o gramado, troncos e caules; para a complementação das folhas e pássaros foram fixados botões de quatro diferentes tamanhos e cores, correspondentes aos quatro modelos de folhas; as mesmas foram elaboradas em cor e tamanho para indicar o ciclo de vida. Todas as partes foram feitas em feltro de acordo com a paleta de cores definida. As dimensões foram planejadas para a atividade ser executada na postura em pé, em tamanho suficiente para a participação de ao menos três crianças simultaneamente. A figura 2 mostra o desenho que será fixado na tenda e a figura 3 como pode ficar após a minifloresta montada.

Figura 2: Imagem que será fixada na tenda

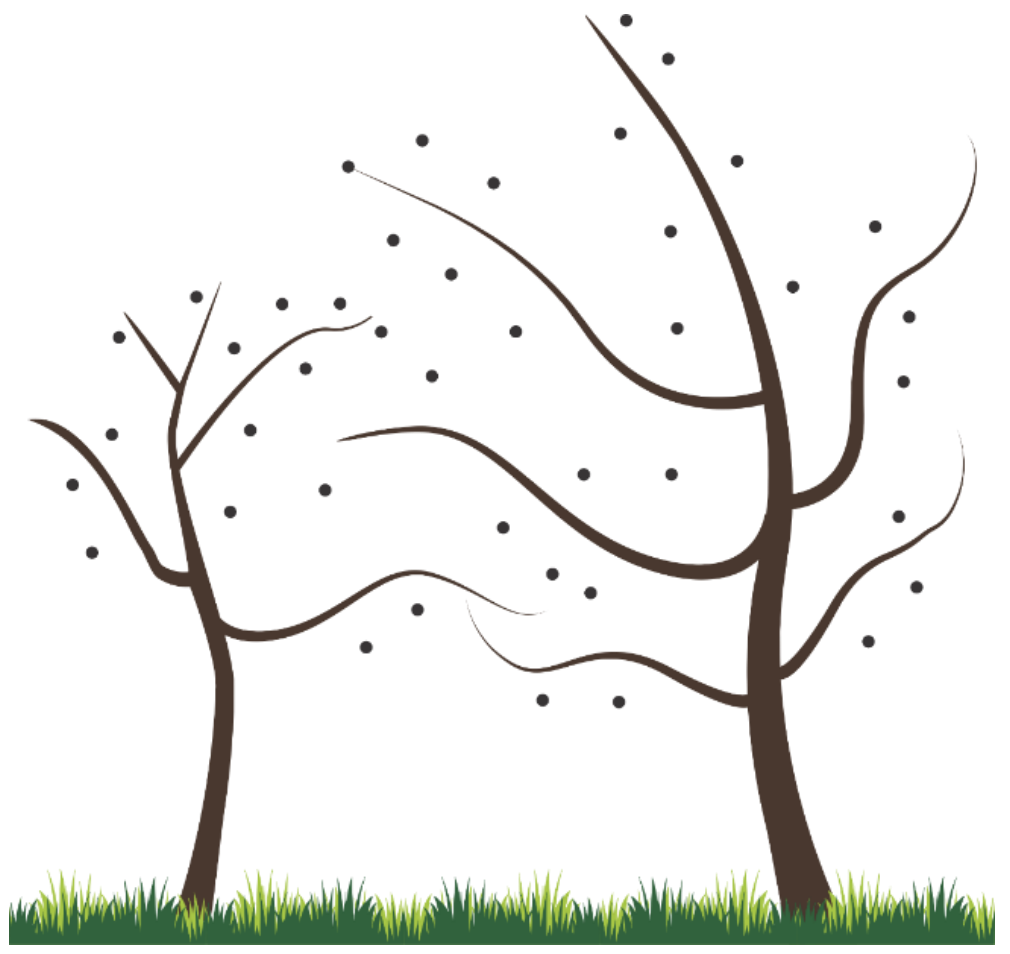

Figura 3: Simulação de como pode ficar a minifloresta já montada 


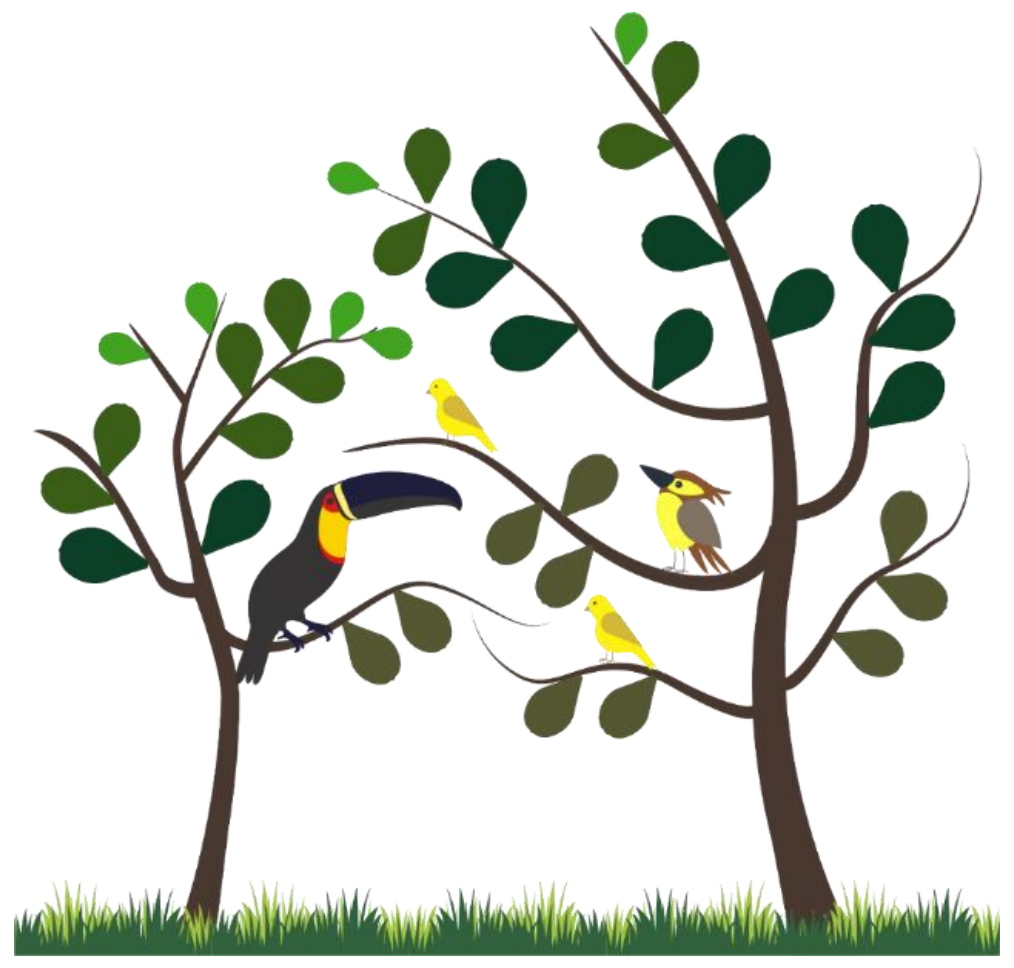

A imagem representativa da floresta foi elaborada de forma a dispor de forma organizada os elementos, facilitando a visualização e a identificação de todas as partes. A disposição das folhas foi planejada de forma que as menores ficassem nas extremidades dos galhos e as de cor verde/marrom nos galhos mais baixos, como se estivessem prestes a cair, indicando o ciclo de vida. Características como equilíbrio das formas, harmonia e curvas suavizadas foram priorizadas. De acordo com Gomes Filho:

A harmonia diz respeito à disposição formal bem organizada e proporcional no todo ou entre as partes de um todo. Na harmonia plena, predominam os fatores de equilíbrio, de ordem e de regularidade visual inscritos em um objeto ou numa composição, possibilitando, geralmente, uma leitura simples e clara. É, em síntese, o resultado de uma perfeita articulação visual na integração e coerência formal das unidades ou partes daquilo que é apresentado, daquilo que é visto, (Gomes Filho, 2009, p. 51).

As folhas, feitas em feltro, possuíam quatro tamanhos e cores diferentes com vincos feitos com cola atóxica colorida, imitando as saliências que uma folha natural apresenta, como mostra a figura 4 . Ao centro foi feito um corte, de tamanho suficiente para abotoar a folha ao botão previamente preso na tenda.

Figura 4: Imagem demonstrando o ciclo de vida das folhas

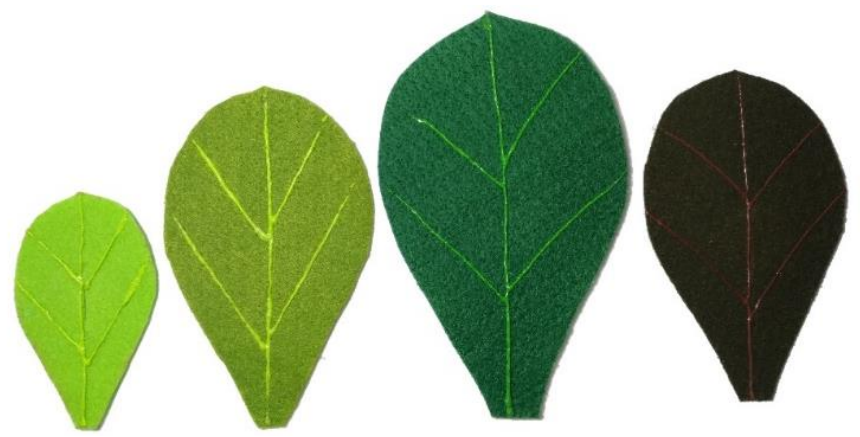




\section{Proposição}

A apresentação do recurso pedagógico para a turma ocorreu no segundo semestre de observação. Nesse momento o menino Bê já estava adaptado a sua nova rotina com o mediador que o acompanhava a semana toda e, embora estivesse frequentando por mais tempo outros locais, como a biblioteca, ainda eram poucas as atividades em que participava com a turma.

O recurso foi montado enquanto as crianças estavam no parque, ao chegarem na sala, como de costume, sentaram-se em roda para as orientações da professora. O menino Bê, ao entrar na sala e visualizar o novo artefato, sentou-se em frente e ficou analisando a novidade. Para iniciar a atividade, a professora contou sobre uma visita que fez a um parque no Rio de Janeiro, depois leu um livro com história sobre animais. Ao fim da história, questionou a turma sobre onde moravam os animais, induzindo a turma a pensar em uma floresta. Falamos sobre as árvores, quais eram suas partes e mostramos as folhas, fazendo com que as crianças refletissem sobre as diferenças visualizadas. Logo surgiu um conceito sobre as folhas: a menor era a 'bebezinha', a segunda maior era a 'adolescente', a terceira era a 'adulta' e a folha marrom era a 'velhinha'. Demonstraram que assimilaram bem o conceito de ciclo de vida das folhas que foi comentado. Durante todo esse tempo Bê permaneceu em sala de aula em frente a tenda, observando, tateando, mas também atento ao que acontecia com seus colegas.

Para iniciar a montagem o combinado era que cada um poderia colocar três folhas na árvore, quanto aos pássaros houve inicialmente um conflito, eram só 4 aves para 12 crianças, mas logo o impasse foi solucionado com diálogo. Houve também dúvidas sobre, onde colocar e como colocar as folhas e aves, que rapidamente com algumas dicas conseguiram desvendar. O menino Bê precisou do auxílio de seu mediador para abotoar as primeiras folhas, e participou durante toda a atividade, como pode ser visto na figura 4.

Figura 5: Crianças interagindo na montagem da minifloresta (foto da autora).

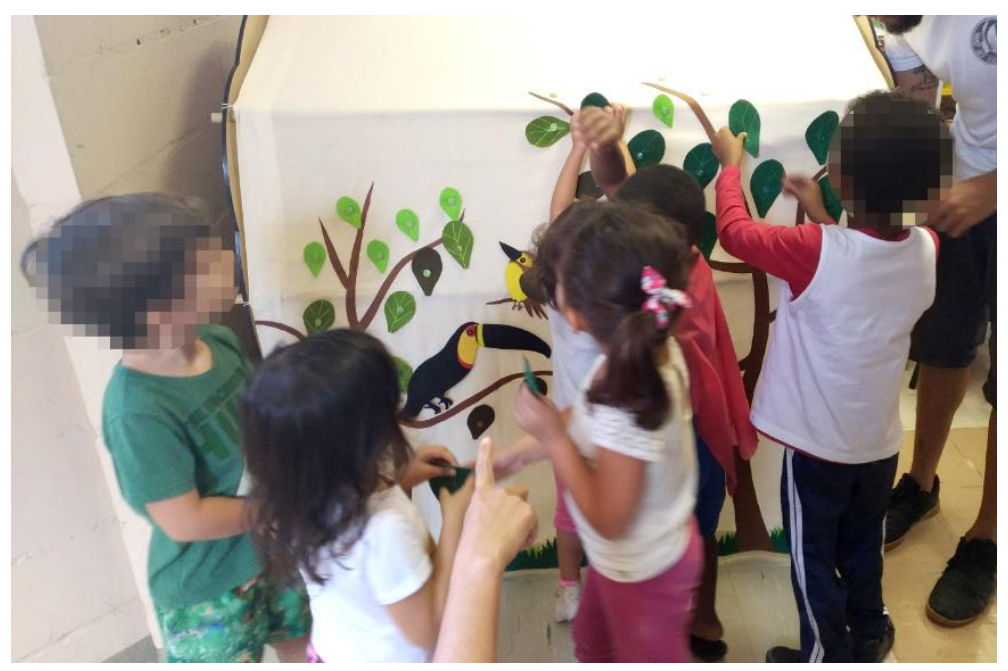

No segundo dia foi lido outro livro também sobre animais, e para a atividade a turma foi dividida em dois grupos, um deveria fazer a montagem e o outro retirar as peças da minifloresta. A professora montou uma atividade lúdica para criação de uma história, onde cada criança tinha que falar uma frase e, a partir dessa frase colocar peças na minifloresta. Bê logo pegou umas folhas para abotoar e seus colegas ajudaram a elaborar a sua frase 'Era uma vez pássaros se ajudando para consertar os ninhos, porque chegou o inverno'. Quando o outro grupo iniciou Bê continuou ali, sendo também o primeiro a retirar as folhas, novamente esse grupo elaborou uma frase para iniciar a história 'Era uma vez duas folhas caindo das árvores', e assim a atividade continuou até que a última peça fosse retirada, (Espanhol, 2018, p. 135).

As atividades demonstrativas foram realizadas durante uma semana, sempre com a

Anais do 9 Congresso Internacional de Design da Informação | CIDI 2019

Proceedings of the 9th Information Design International Conference

Anais do $9^{\circ}$ Congresso Nacional de Iniciação Científica em Design da Informação | CONGIC 2019

Proceedings of the $9^{\text {th }}$ Information Design Student Conference 
colaboração de todos na sala, as crianças inclusive sugeriram mais animais além das aves já presentes. A cada dia uma nova proposta, sempre com a participação de Bê, interagindo com seus colegas. Os momentos em sala de aula junto com a sua turma passaram a ser maiores que o tempo dedicado ao parque, passou a interagir com seus colegas não só nas atividades da tenda, mas em outras também.

Bê já não fugia mais da sala de aula e procurava sempre estar próximo do artefato a que pertencia a tenda. De alguma forma o novo recurso pedagógico proporcionou o acolhimento necessário para que Bê conseguisse estar mais próximo de seus colegas, neutralizando possíveis obstáculos que pudessem dificultar sua presença na sala de aula, inserindo esse indivíduo no contexto de ensino aprendizagem da turma.

\section{Considerações finais}

O projeto realizado na Escola de Educação Infantil contribuiu de forma significativa para a interação do menino Bê com seus colegas. Esse contato mais próximo foi possível por esse projeto de recurso pedagógico ter sido desenvolvido em parceria com a escola e, principalmente levando em consideração características de objetos e locais os quais o menino Bê demonstrava interesse, aliados ao conteúdo que já estava sendo trabalhado por todos no referido semestre.

O recurso atendeu as demandas de um sujeito com autismo e despertou a curiosidade de toda a turma, pois, todos participaram de alguma forma, em ao menos um momento da ideação desse projeto. Segundo Couto 'o ato de projetar permitindo uma contínua participação dos indivíduos e a expressão de suas metas e dos seus desejos faz parte do modo de ver o objeto como fruto de um trabalho interativo entre o designer e o usuário', (Couto, 2017, p. 35).

A disposição das partes, folhas, caules, tronco, aves e gramado, ao todo configuraram uma imagem lúdica e representativa de uma floresta. Árvores e pássaros já fazem parte do cotidiano das crianças na escola, pois, o ambiente é repleto desses elementos naturais. É possível que o interesse de todos pelo novo recurso se configurou pela associação dessa informação aplicada ao Design, aliando um conhecimento prévio a novas formas de apresentação e visualização. $A$ forma como os elementos estavam dispostos na tenda (informação) permitiu que as crianças entendessem onde cada parte (folhas e aves) poderia ser colocado, o que facilitou a atividade de 'montar a minifloresta'.

O Design atuou como um fio condutor para a mediação da interação e do conhecimento para as crianças ali presentes, incluindo Bê, não verbal e com dificuldades de socialização. Houve uma mudança de comportamento desse sujeito principal a partir da apresentação do novo recurso e da informação transmitida pelo mesmo, que remete a elementos já conhecidos por ele, o que proporcionou o acolhimento para que ele participasse junto aos seus colegas da atividade.

O recurso pedagógico projetado na abordagem metodológica do Design em Parceria potencializou a interação entre um sujeito com autismo e seus colegas, tornando esse projeto um recurso facilitador para inclusão de crianças com autismo na Educação Infantil. Entende-se também que o ambiente se tornou um pouco mais acolhedor pelo fato do menino Bê permanecer mais tempo em sala de aula, junto com seus colegas, interagindo e participando das atividades. Segundo Cunha, 'quando estamos trabalhando em ambientes acolhedores, sentimos que a nossa energia criativa e a nossa disposição para a execução das tarefas parecem ser eternas e inquebráveis', (2017).

\section{Referências}

American Psychiatric Association (Org.) (2014). Manual diagnóstico e estatístico de transtornos mentais: DSM-5. 5. ed. Porto Alegre: Artmed. Tradução Maria Inês Corrêa Nascimento.

BRASIL (1998). Constituição da República Federativa do Brasil. Brasília. DF: Senado. 
Centers For Disease Control And Prevention (Estados Unidos) (Org.) (2018). Autism prevalence slightly higher in CDC's ADDM Network. Disponível em: <https://www.cdc.gov/media/releases/2018/p0426-autism-prevalence.html>. Acesso em: 01 maio 2018

Couto, R. M. S. (2017) O design social na PUC-Rio. In: Oliveira, A. J., Franzato, C. \& Gaudio, C. (Org.). Ecovisões projetuais: pesquisas em design e sustentabilidade no Brasil. São Paulo: Blucher, Cap. 3. pp. 29-36.

Cunha, E. (2016). Autismo na escola: Um jeito diferente de aprender, um jeito diferente de ensinar. 5. ed. Rio de Janeiro: Wak Editora.

Espanhol, M. L. (2008). Abrigo multissensorial e atividades pedagógicas: recursos facilitadores para a inclusão de crianças com autismo na Educação Infantil. Orientadora: Renata Vilanova Lima. 183 f. TCC (Graduação) - Curso de Desenho Industrial, Escola de Engenharia, Universidade Federal Fluminense, Niterói, 2018.

Farbiarz, J. L. \& Ripper, J. L. (2011). Design em Parceria: visitando a metodologia sob a perspectiva do Laboratório de Investigação em Living Design da PUC-Rio. In: Coelho, L. A. L. \& Westin, D. (Org.). Estudo e prática em Metodologia em Design nos cursos de pós-graduação. Teresópolis: Novas Ideias, pp. 186-213.

Gomes Filho, J. (2009). Gestalt do objeto: sistema de leitura visual. 9. ed. São Paulo: Escrituras Editora.

Gray, D. E. (2012). Pesquisa no mundo real. 2. ed. Porto Alegre: Penso.

Heller, E. (2013). A psicologia das cores: como as cores afetam a emoção e a razão. São Paulo: Gustavo Gili.

Ribeiro, P. R. \& Oliveira, K. A. S. (2017). Projetos de trabalho na educação infantil. Porto Alegre: Mediação.

Ribeiro, P. R. \& Oliveira, K. A. S. (2017). Projetos de trabalho na educação infantil. Porto Alegre: Mediação.

UNESCO (1994). Declaração de Salamanca: sobre Princípios, Políticas e Práticas em Educação Especial. Salamanca (Espanha). Disponível em: http://portal.mec.gov.br/seesp/arquivos/pdf/salamanca.pdf

Sobre as autoras

Maria Lúcia Espanhol, Mestranda, PUC-Rio, Brasil, mlespanhol@id.uff.br

Renata Vilanova Lima, Doutora, UFF, Brasil, revilanovalima@gmail.com 